\title{
Discussion on Innovative Practice Teaching Model of Software Engineering
}

\author{
Xueli Ren ${ }^{1, a^{*}}$ and Yubiao Dai ${ }^{1, b}$ \\ ${ }^{1}$ School of Computer Science and Engineer, Qujing Normal University, Yunnan 655011, China \\ aoliveleave@126.com, babiaodai@163.com
}

Keywords: Software engineering; Case teaching; Project-based teaching; Innovation

\begin{abstract}
Software engineering practice teaching is a method to understand and deepen theoretical knowledge. The relevant improvements are proposed based on the analysis of the shortcomings in the existing experimental teaching curriculum, and a case is selected carefully from the reality of students to increase students' interest and mastery of knowledge. The case is analyzed and designed in detail that student attendance management system in the paper, which makes the teaching effectiveness of software engineering has been largely improved.
\end{abstract}

\section{Introduction}

The software engineering is a course that combines theory and practice. Through this course, students can understand the whole process of software development and write the relevant documents for each development process, which lay a solid foundation for students to develop software in future. The practical teaching is an important part of teaching that may achieve the goal of cultivating talents of the school, which has a special effect on improving students 'comprehensive quality, cultivating students' innovative consciousness and innovation ability to make students become a compound talent. The quality of practice teaching directly affects the overall teaching, which affects the students' innovative spirit, practical ability and comprehensive quality.

\section{The Problems of Traditional Practice Teaching}

These practical teaching ideas of student-centered, strengthen engineering consciousness and cultivate new talents are put forward according to the goal of comprehensive university construction, that is taking students as the center, engineering consciousness, innovation consciousness and comprehensive ability as the core in cultivating the students' basic skills and requirements to train students to meet the future development needs of high quality, practical ability, innovation and management ability of the compound talents [1-5]. However, there are the following problems in the process of the traditional practice of teaching.

(1)Focusing on training a single point of knowledge make students not achieve mastery

In each phase of the project development, the different cases are selected make students to understand easily the work and tasks of the stages. For example, when the feasibility analysis is carried out, according to the specific requirements of the ordering system to model data flow diagram, but the system of teaching management system is used in the process of data modeling; in the overall design phase of the system, the known data flow diagrams are design the system structure [6-8]; although the content arrangement will help students' understanding of the knowledge, for example, in the practice of data flow diagram of knowledge, the require analysis is given, so students can not really understand the needs of the requirement acquisition process, understand why the changes in requirement analysis are required? In addition, the use of different cases in different stages slit the relationship points of the knowledge, which makes students become difficult to learn the real application of knowledge in a specific project development.

(2)The single form of practice teaching dampens students enthusiasm 
In practice teaching process, most of the contents to practice are verification, and the experiments are done according to the following steps. Firstly, the teacher explain the relevant content, and then students do the same or similar experimental content, in this experimental process students only learned the use of related tools, but not profound understand why we want to do these? [9-11] The way makes practice teaching not achieve the purpose of training students practical ability and creative ability, which affects the enthusiasm and interest of students.

(3)It is difficult to cultivate students' sense of teamwork

As the scale of software is continues expand, the era that individual can achieved software has gone [6-8], today software development projects are carried out in the form of the team; but the existing experimental courses are mainly completed by the single person, that fails to cultivate the ability of student team collaboration, have team awareness, adapt to the future work.

\section{Innovative Practice Teaching}

In order to improve comprehensive engineering quality and cultivate innovative spirit of students, it is necessary to select comprehensive project to train. In order to realize the rapid transformation of roles in the future, it is necessary to cultivate the student's teamwork awareness. In order to achieve the above objectives, the appropriate teaching cases are selected carefully to understand and master the knowledge for students [12-13]. Classroom is the best way for students to learn knowledge, therefore, in order to improve the effect of student learning, the attendance of students in each class of our school are checked, the students who don't registered are recorded in the attendance card, that is signed by the teacher and submitted to the office, the absence students within one week will be counted of every classes and feedback to the class teacher to verify. It has been a work in recent years, but until now this work are carried out by hand, students also understand the process. Therefore, the attendance management system is taken as an example for practical teaching. Meantime all the experiments are grouped in order to enable students to truly experience the team spirit and sense of collaboration, and need to write the appropriate development documentation to develop and exercise students' language expression skills in each stage.

Students are required to examine the process by asking the relevant personnel from the business needs, and then the relevant information collected are organized into a document, that is the basis for subsequent systematic analysis and design. This process of practice, the participation of students is high, and can profoundly understand the importance of each stage of the task and the coherence between tasks, and fully enhance the students thirst for knowledge and desire to succeed, a great mobilization of the students, the sense of participation and performance awareness. The student attendance management system is as an example, the detail system analysis and design processes are discussed in the next content.

System Analysis. The business investigation of the student attendance system is finished the document, and the documents related to the attendance information table, student basic information, such as the table are collected in the process of course of the business investigation. The data flows are analyzed in the system, then the two data flow diagrams are drawn and shown in Fig. 1 and Fig.2. There aren't the corresponding data dictionaries in the paper due to limited space. 


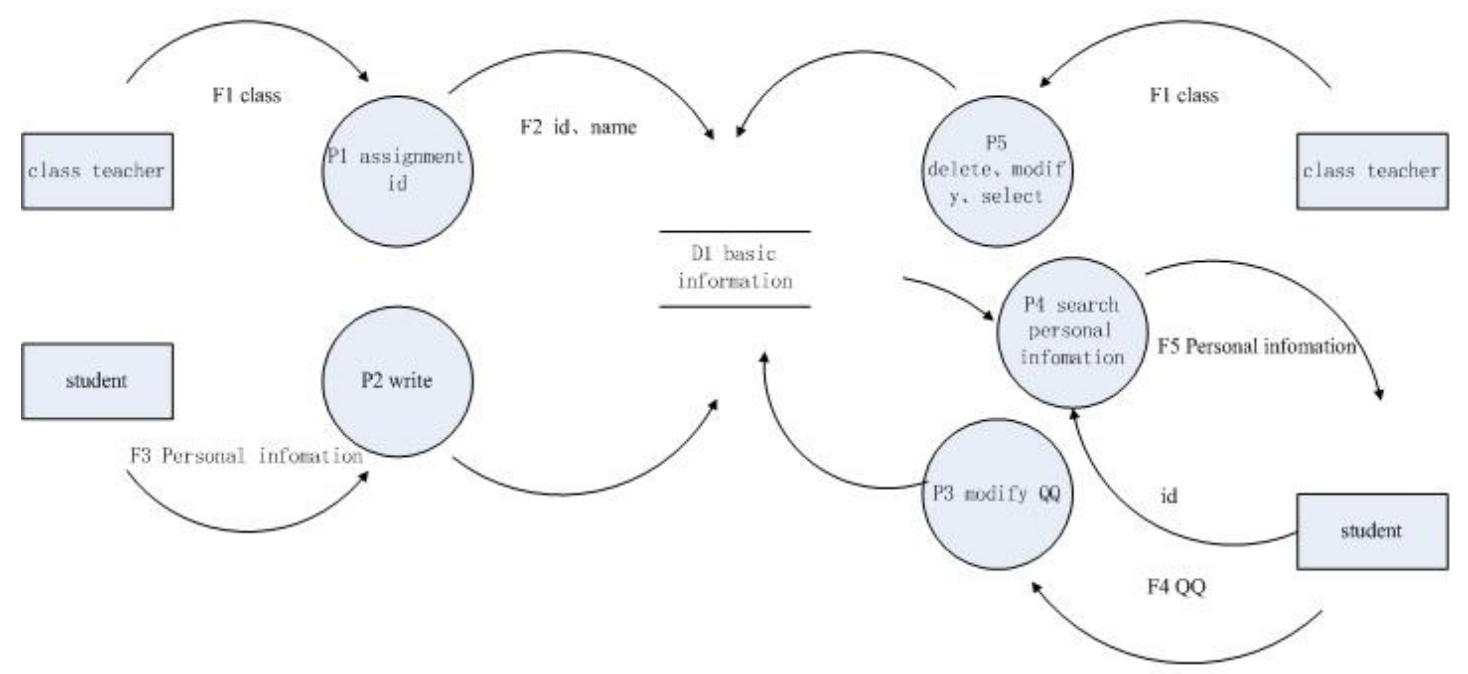

Figure 1. The data flow chart of Student basic information management

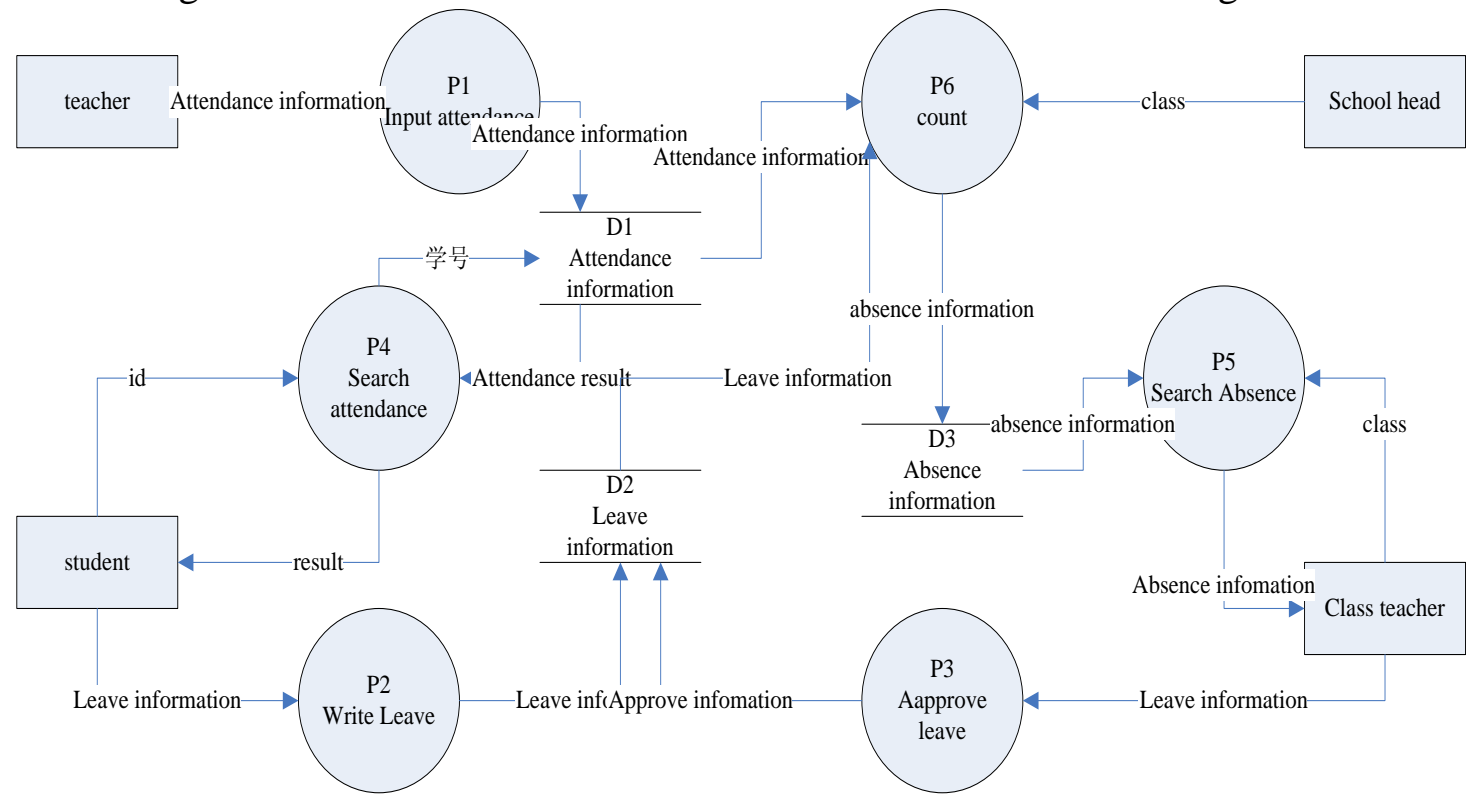

Figure 2. The data flow diagram of attendance management

The ER diagram of the system is shown in Fig. 3.

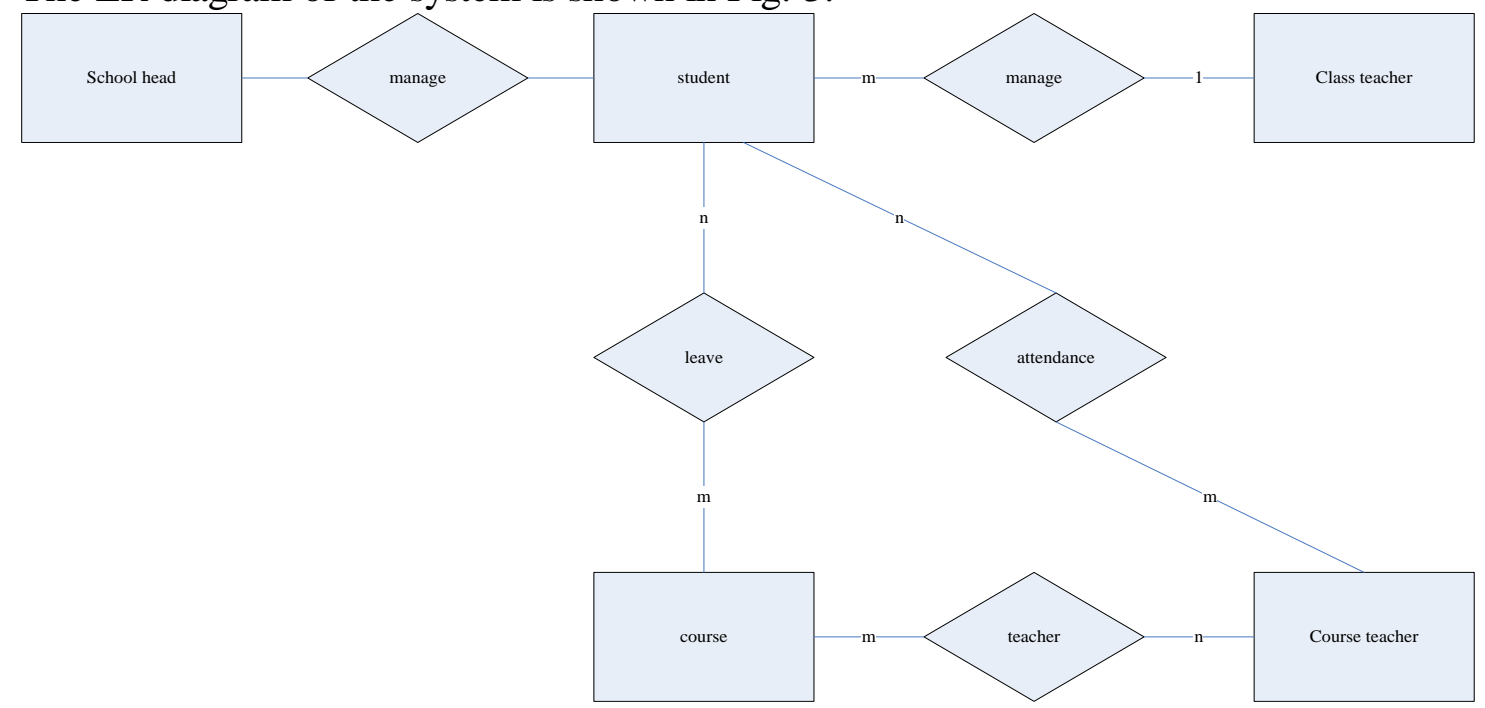

Figure 3. The ER diagram of the system 
System Design. According to the system data flow diagram, the function module diagram is shown in Fig. 4:

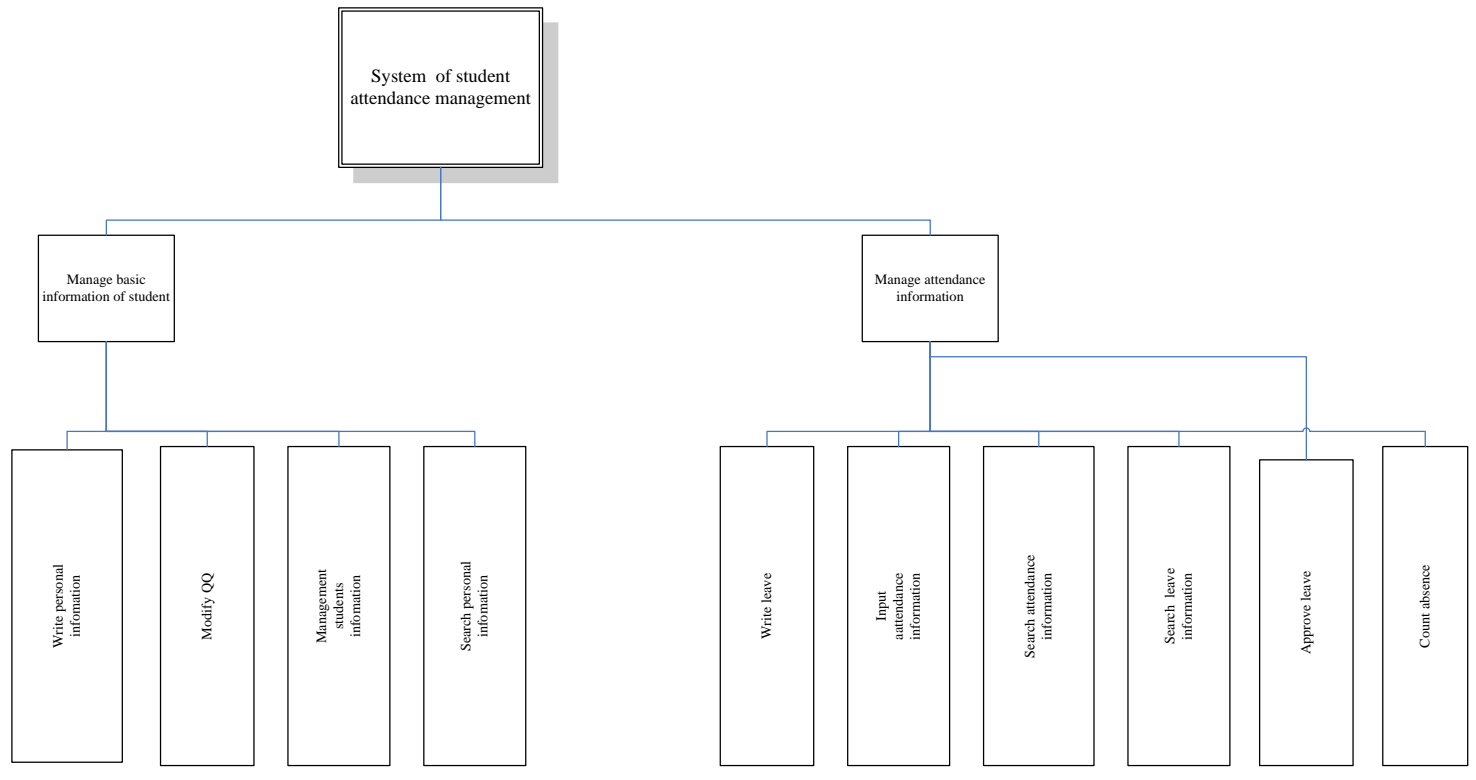

Figure 4. The function module diagram

Design Data Structure of System. The data structures are designed according to data and table related that are collected in the period of business survey system. They aren't given in the paper as these content are introduced in detail in the course of database, therefore, this paper will not repeat them.

\section{Summary}

Software engineering course is a practical course, but the traditional way of teaching failed to reach training students' practical ability, innovation and cooperation ability, that has seriously affected the enthusiasm of the students and the learning interest. A teaching case is selected carefully; students are grouped in order to improve students' sense of participation and awareness, in that the teaching effect is improved. Finally, the analysis and design process of the case are given in detail, that provide a good case support to teach and communicate between teachers and students..

\section{References}

[1] Liu Zai-ying, Yang Ping and Zhang Li-xiao Probing into the Practice Teaching of Programming Design Courses[J]. Research and Exploration in Laboratory. 2013.10

[2] Ding haiyan. Discussion on practice teaching mode of Basic Visual programming course [J]. Research and Exploration in Laboratory. 2013.10

[3] Wang yanping, li haiyan and xubo. Reform of UML Instance Teaching[J]. Research and Exploration in Laboratory. 2011.9:221-223

[4] Liu guangrong. Integrated teaching mode of $\mathrm{C}$ programming experiment teaching [J]. Research and Exploration in Laboratory. 2013.10: 350-352

[5] Wang jianli, Chen guoping. Collaborative innovation mechanism of University Practice Teaching [J]. Research and Exploration in Laboratory. 2013.10:138-140

[6] Zhang haifan. Introduction to Software Engineering [M]. Beijing: tsinghua university press, 2013.8 
[7] Roger S. Pressman. Software engineering: A Practitioner Approach [M]. Machinery Industry Press, 2011.5

[8] Ian Sommerville. Software Engineering [M]. Machinery Industry Press, 2011.5

[9] Zhong Xiuyu, Liu Yuechang. Discussion on cooperative innovation practice teaching system of software engineering specialty [J]. Research and Exploration in Laboratory,2014.4:175-179

[10] Chen shuang. Experimental teaching reform of Applied Talents Training Mode [J]. Research and Exploration in Laboratory,2012, 31(8): 1-3

[11]Zhang Zhongfu. Establishing practice teaching system centered on ability training [J]. Technology and management on laboratory. 2011, 28(2): 11-14

[12] Liu picai. Exploration on practice teaching reform of software engineering specialty [J]. Research and Exploration in Laboratory, 2007.12:238-240

[13] Guo lingling, Yuan man. Case driven research-based teaching[J]. Computer Education, 2011.3:75-78 